\title{
Body sway during long-term standing and as affected by pure tones'
}

CAROLYN K. BENSEL, E. DZENDOLET ${ }^{2}$ AND H. L. MEISELMAN DEPARTMENT OF PSYCHOLOGY, UNIVERSITY OF MASSACHUSETTS

Sixty students, male and female, were used as Ss to test the effect of a 1,000-Hz, 5-sec tone at 0,70 , and $90 \mathrm{~dB}$, on standing sway. In general, antero-posterior sway was greater than lateral, and males swayed more than females in both directions. In addition, males increased their sway in time, whereas females did not. Only lateral sway in the 5-sec interval after the presentation of the tone increased, and only after 10,15, and $20 \mathrm{~min}$ of standing, with a maximum at 15 min. Amplitude of lateral sway appeared independent of bodily characteristics, and is suggested as being more useful for comparing Ss than is antero-posterior sway.

The concern of this experiment was two-fold; the first was to see what changes took place in amplitude of body sway over a 20 -min duration, and the second was to see what effect a $1,000-\mathrm{Hz}$ tone, up to $90 \mathrm{~dB}$ SPL (re: 0.0002 dynes $/ \mathrm{cm}^{2}$ ), had on body sway. Because there appeared to be no earlier studies of long-term standing, the pertinent literature on short-term standing will be cited.

Two experiments (Fearing, 1924a; Miles, 1950) using the Miles "ataxiameter" (Miles, 1921) showed that normal sway, recorded for 2-min periods of time from Ss who were standing in their shoes with their heels touching and feet at a $45 \mathrm{deg}$ angle, was about $10 \%$ greater in males than in females. The ataxiameter was a mechanical device which automatically and separately totaled the amount of sway in the forward, right, backward, and left directions. Similarly, Travis $(1944,1945)$ showed that females were superior to males in the "stabilometer task" which involved standing with the feet together on a movable platform and adjusting the posture so that equilibrium was maintained.

Fearing (1924a) also compared the relative amounts of sway in the antero-posterior and lateral directions in Ss whose eyes were closed. He found, using 2-min recordings on the Miles ataxiameter, that antero-posterior sway was approximately $70 \%$ greater than lateral sway when the feet were at a $45 \mathrm{deg}$ angle, but only $12 \%$ greater when the feet were held together in the Romberg position. Edwards (1942) confirmed this finding, using 1-min ataxiameter recordings, and also noted that antero-posterior sway was $70 \%$ greater than lateral sway.

Experiments investigating the effects of repeated trials involving 1- or 2-min periods on the Miles ataxiameter over many sessions have indicated either no change in sway amplitude (Edwards, 1942; Fisher, Birren, \& Leggett, 1945) or a substantial decrease (Miles, 1921; Fearing, 1924b). Travis $(1944,1945)$ reported improvement in stabilometer scores over eight 1-min trials administered in a single session.

Correlations between height and weight, and amplitude of sway have generally been negligible (Fearing, 1924a;. Travis, 1945), although there have been some slight positive correlations with height reported (Fearing, 1924a; Miles, 1950). Travis (1945) reported a high correlation $(r=.76)$ between stabilometer seore and the value obtained by measuring the distance from the center of gravity to the platform on which the S stood, and dividing this distance by the weight of the $S$.

The effect of auditory stimulation on human sway was first extensively investigated by Békésy (1935) who used pure tones ranging from 200 to $5,000 \mathrm{~Hz}$, and intensities up to $134 \mathrm{~dB} \mathrm{SPL}$ (re: 0.0002 dynes $/ \mathrm{cm}^{2}$ ). The response studied was movement of the S's head. He found that the absolute threshold for the most sensitive of four Ss occurred when the tone was $92 \mathrm{~dB}$. This S's absolute threshold and another's did not vary much with frequency. The thresholds of the other two Ss did vary considerably with frequency. The mechanism whereby head movements occurred to sound stimuli was presumed to be by means of a pressure on the wall of the labyrinth, which then stimulated the otoliths. The pressure was assumed to be produced by eddy currents in the perilymph in response to the sound.

Recent experiments have not been directly concerned with auditory effects. Revusky, Moore, and Dzendolet (1965) attempted classical conditioning of body sway. Their conditional stimulus was a $1,000-\mathrm{Hz}$ tone of $62-\mathrm{dB}$ SPL and $5.5-\mathrm{sec}$ duration, presented on a background of 62-dB SPL white noise. The unconditional stimulus was a sinusoidal electrical current passed between the S's mastoid processes by means of fluid electrodes. The frequency of the stimulus was $0.5 \mathrm{~Hz}$ and lasted $5 \mathrm{sec}$. The current amplitude was adjusted to be between 0.165 and 0.175 $\mathrm{mA}$ for each $\mathrm{S}$. Whole body sway was measured by means of two strain gauges under a platform on which the $S$ stood. Lateral movements of the $S$ produced electrical changes via the strain gauges, and these changes were recorded on an oscillograph. Sway was measured as the maximum peak-to-peak amplitude within a given interval. Specifically, the sway in the 15-sec interval before the tone went on was compared with the sway during the tone and the $15-\mathrm{sec}$ interval immediately afterward. They reported no significant increase or decrease in sway because of the tone itself. They concluded that conditioning had occurred, because the lateral sway in the test trials (trials in which only the tone was presented) of the group which received the paired tone and electrical stimulus was greater than the sway in the test trials of the other control group used. However, there was no significant difference between the sway in the test trials of their conditioning group, and the test trials of the group which received only the tone.

In a similar experiment, but using a 1,000-Hz tone of $70-\mathrm{dB}$ SPL and 5.5-sec duration as the conditional stimulus presented on a background of $70-\mathrm{dB}$ SPL white noise, Fernald and Moore (1966) found that some suppression of lateral sway occurred during the combined interval of the tone duration and 15 -sec interval immediately after. This suppression was greatest in the group which received only the tone and not electrical stimulation. They also noted that an overall increase in amplitude of swaying occurred as a function of time.

In a third similar experiment, Pezzoli and Moore (1966) again noted suppression of lateral sway to the conditional stimulus. The conditional stimulus was the same as in the experiment above.

\section{Subjects}

\section{METHOD}

These were 60 undergraduate students at The University of Massachusetts. They were selected from a larger group on the basis of a pre-experiment interview, so that no $S$ reported a history of fainting spells, serious head injury (concussion or fracture), serious foot or leg injury, or recent illness. Ss were not to be taking any medication at the time of the experiment, with the possible exception of vitamins. Ss were either paid for the experiment or were given credit toward fulfillment of a course requirement. Ss for a no-tone group were selected and run first, and the rest were randomly assigned to one of two groups, a $70-\mathrm{dB}$ and a $90-\mathrm{dB}$ tone group, which were run concurrently. Ten mates and 10 females were in each group.

\section{Apparatus}

The stimulus was a $1,000-\mathrm{Hz}$ pure tone (General Radio Co., beat frequency audio generator, Model 1304-A), delivered to both ears via earphones (Grason-Stadler Model TDH39 with Model MX41/AR cushions). The tone was alternated with white noise (Grason-Stadler Noise Generator Model 901B) at 70-dB SPL. 
Presentation of the tone was programmed by a Gerbrands type programmer in conjunction with a timer (Hunter Model 100-C, set for $5.0 \mathrm{sec}$ ) for the duration of the tone and an electronic switch (Grason-Stadier Model $829 \mathrm{E}$, set for 50 -msec rise-decay time) to avoid transients.

The sway transducer was a square platform of $3 / 4$ in. plywood supported at the center of each side of the platform by the end of each of four short, horizontally positioned steel bars. The ends of the bars extended under the platform and made contact with it by means of machine screws which firmly attached the platform to the bars. The other ends of the bars were rigidly fastened to a steel framework below the platform. Strain gauges were applied to all the bars. The two gauges on opposing bars were made part of a Wheatstone bridge circuit so that a force applied at any point of the platform, except at the center, along a line joining the opposing bars, would create an imbalance in the bridge circuit. The same situation held for the other two strain gauges. No sensation of movement or rocking of the platform occurred if the $S$ shifted his weight.

The outputs of the separate bridge circuits were led into preamplifiers (Grass Instrument, Model 5P1), and displayed on separate channels of a polygraph (Grass Instrument, Model 5). In this way, a force on any portion of the platform was resolved into two mutually perpendicular forces, and the amplitudes were displayed on separate channels. The $S$ was positioned so that the forces or sways were those in the antero-posterior and lateral directions.

\section{Procedure}

The $\mathbf{S}$ was asked to remove his shoes and was then blindfolded and the earphones were put on his head. The following instructions were then read to him:

Your task during this experiment is to stand on the platform which I just pointed out to you. We would like you to stand on the platform without moving your feet or legs once their position has been set. without moving your hands or arms-please clasp your hands and let them hang limply in front of you-and without moving your head unnecessarily. We do not want you to stand rigidly as if at attention. It is important that you relax. But try to relax without moving your feet and legs, your arms or your head. Are there any questions?

If there were any questions, the instructions were either reread, or otherwise made clear. The $S$ was then helped to assume the proper stance in the center of the platform with his heels together and feet at about 45 deg to each other, and instructed to stand so that his weight was evenly distributed on both feet.

Preamplifier sensitivity was set at $0.05 \mathrm{mv} / \mathrm{cm}$ for all Ss. The system was calibrated by placing a $2.0 \mathrm{~kg}$ mass at $25 \mathrm{~cm}$ from the center of the platform. This mass produced a deflection of $1.0 \mathrm{~cm}$ with the preamplifier sensitivity set at $0.02 \mathrm{mv} / \mathrm{cm}$.

The experimental session began when the $S$ was in the proper position on the platform. All Ss remained in this standing position for $20.5 \mathrm{~min}$. For the Ss in the no-tone group, sway recordings of 30 -sec duration only were made starting at $0,5,10,15$, and 20 min after the start of the session. Such 30 -sec periods were designated as Blocks (B). The measure of sway used was determined by first dividing the sway record in each block into six 5-sec intervals. Within each such interval, the difference, in $\mathrm{mm}$, between the maximum and minimum pen deflections was determined, and this difference was defined as the sway response in that interval, and used as data for the analysis.

For $S s$ in the 70 and $90-\mathrm{dB}$ tone groups, the entire 20.5 -min session was first divided into 4130 -sec intervals. Within each such interval, the 5.0-sec tone was programmed to occur randomly only once, with the restriction that two tones would not occur immediately after one another, as at the end or beginning of two intervals. The same pattern of tone presentations was used for all Ss. Because the tones were distributed throughout the entire session, sway recording of the whole session was made, but the analysis was based on the same blocks as used for the no-tone group. Within each block, the sway in three consecutive 5.0-sec intervals was determined. These were the interval immediately before the tone $\left(T_{1}\right)$, the interval during the tone $\left(T_{2}\right)$, and the interval immediately after the tone $\left(T_{3}\right)$. When all three groups were compared, only the sway in the three intervals of the no-tone group corresponding to those in the other two groups in which a tone was presented, was used in the analysis. The remaining intervals in the blocks of the no-tone group were not used in this analysis.

\section{RESULTS}

Antero-posterior and lateral sways were assumed to be independent, and were subjected to separate analyses of variance. In addition, the no-tone group was analyzed twice; once was by itself, and the other was with the two tone groups. It should also be emphasized that the sway values reported are those from the polygraph record, and are not the values through which the S's head moved.

\section{Separate Analysis of the No-tone Group}

The overall arithmetic mean of antero-posterior sway amplitude was greater than that of lateral sway, the values being 7.61 vs 6.49 $\mathrm{mm}$, respectively. This relationship held for virtually every $\mathbf{S}$ in every block.

Males exhibited a greater sway amplitude than did females in both the antero-posterior direction $(F(1,18)=9.36, p<.01)$ and the lateral direction $(F(1,18)=9.48, p<.01)$. In addition, a main effect of Blocks, i.e., a change in sway with time, was also found, but only for the antero-posterior direction $(F(1,72)=4.44$, $\mathrm{p}<.001)$. A clarification was provided by the Sex-by-Blocks interaction, which was significant for both the antero-posterior direction $(F(4,72)=2.66, p<.05)$, and the lateral direction $(F(4$, $72)=3.08, p<.05)$. The data showed that the antero-posterior sway amplitude of males increased from 8.40 to $11.00 \mathrm{~mm}$, and the lateral sway from 7.23 to $9.12 \mathrm{~mm}$ over the $20.5 \mathrm{~min}$ period of the experiment. For the females, on the other hand, there was a nonsignificant antero-posterior sway increase from 6.28 to 6.64 $\mathrm{mm}$, and a lateral sway decrease from 5.31 to $4.83 \mathrm{~mm}$.

\section{Analysis between all Groups}

The primary interest in this analysis was whether or not a significant difference in sway occurred in the three intervals, and if this difference was influenced by sex; by blocks, i.e., time, or by groups, i.e., tone intensity. A significant Interval effect was present, but in the lateral direction only $(F(2,108)=3.83$, $\mathrm{p}<.05$ ). The lateral sway amplitude was essentially constant for the first two Intervals $\left(T_{1}\right.$, before stimulation, $=5.53 \mathrm{~mm}$; and $T_{2}$, during stimulation, $=5.46 \mathrm{~mm}$ ), and increased in the final Interval $\left(\mathrm{T}_{3}\right.$, after stimulation, $=6.10 \mathrm{~mm}$ ).

The Intervals-by-Groups interaction was not significant for either direction of sway, but inspection of Table 1 indicates which groups contributed to making the intervals effect significant. As can be seen, $\mathrm{Ss}$ in the 70-dB group showed a decrease in lateral sway for $T_{2}$, and an increase in $T_{3}$. On the other hand, $S s$ in the 90-dB group showed a continuing increase in both $T_{2}$ and $T_{3}$. There was no such relationship with antero-posterior sway.

The effect of time was indicated by the Intervals-by-Blocks interaction, which was significant only for lateral sway $(F(8,432)$ $=2.40, p<.05$ ). Presentation of a tone had no apparent effect during $B_{1}$ or $B_{2}$. During $B_{3}$ and $B_{4}$, however, sway increased in $T_{2}$ and $T_{3}$. During $B_{5}$, sway amplitude was high in $T_{1}$, decreased in $T_{2}$, and increased in $T_{3}$. The high value for $T_{1}$ came from the high values of a few Ss in the 70-dB group, and it is not certain that this high value is representative. If the data from the 70-dB and $90-\mathrm{dB}$ groups are inspected separately, the above generalization holds for both, except that sway in $T_{3}$ at $70 \mathrm{~dB}$ was generally higher than at $90 \mathrm{~dB}$.

Although the Groups-by-Blocks-by-Intervals interaction was not significant, a plot of the data (Fig. 1) will permit the evaluation of the Blocks-by-Intervals interactions within each group. The higher level of lateral sway for the no-tone group is an artifact, due, apparently, to the fact that $S s$ in this group were run early in one semester, whereas the $S s$ in the other two groups were run from those available at the end of the same semester. The changes of 


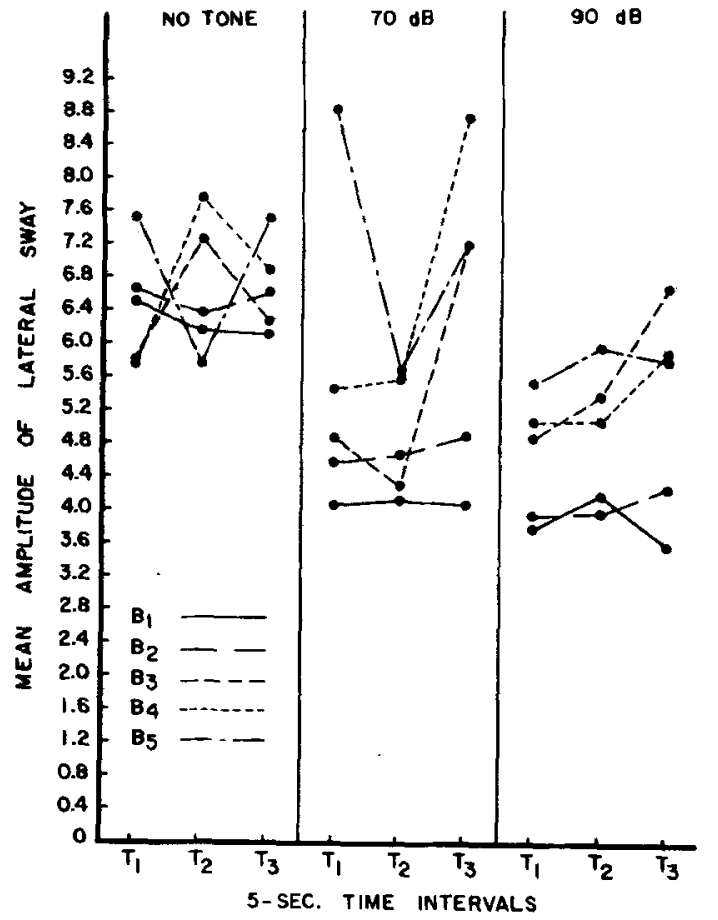

Fig. 1. Lateral sway amplitude of males and females combined, showing the effect of a 5-sec, $1,000-\mathrm{Hz}$ tone, which was presented during $T_{2} . B_{1}, B_{2}$, etc. indicate 30-sec intervals occurring once every $5 \mathrm{~min}$, so that $B_{5}$ signifies a time $20 \mathrm{~min}$ after the start of the experiment. It can be seen that the sway during $T_{3}$ increased with time, to a maximum value at $B_{4}$. The amount of increase was greater for $70 \mathrm{~dB}$ than for $90 \mathrm{~dB}$.

sway as a function of intervals, however, should not have been affected by this difference in Ss. Figure 1 indicates that the variations in sway over blocks is essentially random in the no-tone group. In the 70- and 90-dB groups, however, the tendency is for $B_{1}$ and $B_{2}$ to be nearly the same, for $B_{3}$ and $B_{4}$ to rise steeply at $T_{3}$, and for $B_{5}$ to decrease at $T_{3}$. One exception was the point at $T_{1}$ for $B_{s}$ at $70 \mathrm{~dB}$, which was mentioned earlier. In general also, there was a tendency for sway to increase with blocks. This was shown by the significant effect of Blocks for both the anteroposterior direction $(F(4,216)=10.98, p<.01)$ and the lateral direction $(F(4,216)=6.26, p<.05)$. The Blocks-by-Sex interaction was significant $(F(4,216)=2.88, p<.05)$ only for the lateral sway direction. In this direction, male sway amplitude was monotonic increasing with time $\left(B_{1}=5.62 \mathrm{~mm}, B_{5}=8.71 \mathrm{~mm}\right)$, whereas female sway amplitude remained virtually constant after a slight initial increase $\left(B_{1}=3.82, B_{5}=4.54\right)$. For the anteroposterior direction, both males and females showed a monotonic increasing function with time. The latter increase for females was not shown in the separate analysis of the no-tone group.

The results of the analysis also indicated that males swayed significantly more than females, for both the antero-posterior direction $(F(1,54)=23.58, p<.01)$ and also the lateral direction $(F(1,54)=13.05, p<.01)$. The Sex-by-Groups interaction was significant for antero-posterior sway $(F(2,54)=3.34, p<.05)$ and for lateral sway $(F(2,54)=3.67, p<.05)$. For both sway directions, females in the 70-dB group showed smaller amplitudes than in either of the other two groups, in which sway amplitudes were approximately the same. Sway amplitudes in the 90-dB group for both males and females tended to converge toward one another.

\section{No-Tone Group}

\section{DISCUSSION}

Inspection of the data of the no-tone group generally verified the conclusions of earlier experiments which used shorter dura- tions of standing. In the first portion of the session, mean amplitude of sway, in both directions, was about $35 \%$ greater for the males than for the females. At the end of the session, i.e., 20.5 min later, it was about $75 \%$ greater.

Earlier experiments reported that antero-posterior sway amplitude was about $70 \%$ greater than lateral (Fearing, 1924a; Edwards, 1942). In the present experiment, antero-posterior sway amplitude of the no-tone Ss was about $17 \%$ greater than lateral sway at the beginning of the session, and approximately $30 \%$ greater at the end. This was true for both males and females. The possible source for the difference in these findings may be that the Ss wore shoes in the earlier experiments, and either wore only socks or were bare-footed in this one. It is possible that the wearing of shoes supplies a slight stiffening of support under the feet in the antero-posterior direction, much like the wearing of skis, so that the body's center of gravity could be shifted forward more than would otherwise be possible.

Earlier research had indicated a lack of correlation of sway amplitude either with height, or with weight. However, a relatively high positive correlation $(\mathrm{r}=.76)$ had been obtained between sway amplitude and a measure using the center of gravity (Travis, 1945). In the current experiment, another measure was used to characterize the S's body, and a Pearson product-moment correlation coefficient was computed between this new measure and the $S$ 's sway amplitude. The new measure was obtained by first taking $55 \%$ of the S's height, which is the position of his center of gravity (Hansen, Cornog, \& Hertzberg, 1958, p. 283). This distance was multiplied by the S's weight, and the product was correlated with the S's mean sway over all blocks. Separate correlations were computed for antero-posterior and lateral sways.

The rationale behind the use of this product as a measure of sway was to consider the S's sway in its simplest form, which was that of a mass on a lever whose pivot point was on the platform. Any movement of the mass from its equilibrium position would imbalance a pair of the strain gauges in a particular direction, and the greater the sway to one side, the greater the imbalance. Thus, this measure was not concerned with only the angle through which a $S$ might move, but rather with how fas the mass of the body was shifted during sway.

The Pearson correlation coefficients were significant for both antero-posterior sway $(r=0.69, \mathrm{df}=19, \mathrm{p}<.01)$, and lateral sway $(r=0.45, d f=19, p<.05)$. Correlation coefficients computed separately for each sex in both sway directions were not statistically significant, however. The coefficients in the anteroposterior direction for males and for females were 0.42 and 0.41 , respectively, whereas those in the lateral direction were 0.01 and 0.10 , again, for males and for females, respectively. These coefficients indicate that lateral sway, because it is less correlated with the height-weight measure used here, may be dependent on some other body characteristic, perhaps one which may be seated in the vestibular apparatus itself. Because of its independence of gross body characteristics, lateral body sway may be the more appropriate response measure to use in comparing Ss rather than antero-posterior sway.

\section{All Groups}

As mentioned earlier, Békésy (1935) found an increase in head movements with a $1,000-\mathrm{Hz}$ tone at intensities greater than $92 \mathrm{~dB}$, whereas other investigators found either lateral body sway suppression with the same frequency tone at $70 \mathrm{~dB}$ (Fernald \& Moore, 1966; Pezzoli \& Moore, 1966), or lateral body sway enhancement at $62 \mathrm{~dB}$ (Revusky et al, 1965). In the current experiment, inspection of Table 1 , which combines males and females, and also blocks of time, shows a suppression of lateral body sway at $70 \mathrm{~dB}$, in agreement with Fernald and Moore and Pezzoli and Moore. That Revusky et al found enhancement stems from the fact that they measured sway in an interval which included the presentation of the tone and also the $15 \mathrm{sec}$ immediately after. From the data of the current experiment, it is clear that the period after the tone, i.e., $T_{3}$, is the time in which increased body sway occurs. Inclusion of this interval, because of the sway measure used, would clearly lead to noting that an 
Table 1

Body sway amplitude in mm of the record, in standing Ss during 5 -sec intervals before $\left(T_{1}\right)$, during $\left(T_{2}\right)$, and after $\left(T_{3}\right)$ presentation of a $1,000-\mathrm{Hz}$ tone.

\begin{tabular}{|c|c|c|c|c|c|c|}
\hline Tone Intensity & \multicolumn{3}{|c|}{ Lateral Sway } & \multicolumn{3}{|c|}{ Antero-Posterior Sway } \\
\hline $0 \mathrm{~dB}$ & $\begin{array}{r}T_{1} \\
6.45\end{array}$ & $\begin{array}{r}T_{2} \\
6.65\end{array}$ & $\begin{array}{r}T_{3} \\
6.67\end{array}$ & $\begin{array}{r}\mathrm{T}_{1} \\
7.81\end{array}$ & $\begin{array}{r}\mathbf{T}_{2} \\
7.87\end{array}$ & $\begin{array}{r}\mathrm{T}_{3} \\
7.16\end{array}$ \\
\hline $70 \mathrm{~dB}$ & 5.54 & 4.86 & 6.39 & 7.34 & 7.54 & 8.26 \\
\hline $90 \mathrm{~dB}$ & 4.60 & 4.89 & 5.22 & 6.91 & 7.12 & 7.08 \\
\hline
\end{tabular}

increase occurred. However, Fig. 1 suggests that much of the overall decrease in lateral sway may be due to the exceptionally high value of $T_{1}$ in $B_{3}$. Without further experiment, it is not clear whether or not this high value for $T_{1}$ in $B_{5}$ is usual, and if the observed suppression of sway would still occur. On the other hand a slight tendency for an increase of antero-posterior sway at $70 \mathrm{~dB}$ can be seen in Table 1 .

At $90 \mathrm{~dB}$, the observed trend toward increased sway in both the lateral and antero-posterior directions, although not significant, is in agreement with Bèkésy's findings. It is probable that an increase in tone intensity above $90 \mathrm{~dB}$ would show a greater increase in sway during the period of the tone in both lateral and anteroposterior directions.

The largest effect of the tone appeared to be an increase in lateral sway in the interval immediately after the tone. This was particularly marked at $70 \mathrm{~dB}$, but did not seem to hold for antero-posterior sway at $90 \mathrm{~dB}$ (Table 1). Because no such effect was found in the no-tone group, it is likely that the effect is tied to the tone itself. Furthermore, Fig. 1 shows that the increased sway occurred primarily at $B_{3}$ and $B_{4}$ for both intensities, and also at $B_{5}$ with the $70 \mathrm{~dB}$ intensity. It is not clear why such a relatively greater increase in sway occurred at $70 \mathrm{~dB}$ during $T_{3}$, and not at $90 \mathrm{~dB}$.

What seems clear is that a pure tone at a relatively low intensity can affect body sway under certain conditions. Therefore, one aspect of the results of this experiment should be emphasized. As shown in Fig. 1, the greatest effect of the tone, the increase in sway during $T_{3}$ at both tone intensities, occurred after the $S$ had been standing for 10-15 min. A decrease appeared to take place at $20 \mathrm{~min}$ although this experiment did not follow the effect beyond this time. Because of the increase in sway due to the tone, the use of sway amplitude as a response measure in the presence of a tone, e.g., in a classical conditioning situation in which sway is used as the conditional response and the tone is used as a conditional stimulus, may lead to the erroneous conclusion that conditioning had taken place when in fact it had not.

\section{REFERENCES}

EDWARDS, A. S. The measurement of static ataxia. Amer. J. Psychol, 1942, $55,171-188$.
FEARING, F. S. The factors influencing static equilibrium. I. J. comp. Psychol., 1924a, 4, 91-121.

FEARING, F. S. The factors influencing static equilibrium. II. J. comp. Psychol, 1924b, 4, 162-183.

FERNALD, C. D., \& MOORE, J. W. Vestibular sway: parameters of the eliciting stimulus. Psychon. Sci., 1966, 4, 55-56.

FISHER, M. B., BIRREN, J. E., \& LEGGETT, A. L. Standardization of two tests of equilibrium: the railwalking test and the ataxiagraph. $J$. exp. Pyychol, 1945, 35, 321-329.

HANSEN, R., CORNOG, D. Y., \& HERTZBERG, H. T. E. Annotated bibliography of applied physical anthropology in human engineering. WADC Technical Report 56-30. 1958. Aero Medical Laboratory, WrightPatterson Air Force Base, Ohio.

MILES, W. R. Static equilibrium as a useful test of motor control. J. incust. Hyg., 1921, 3, 316-361.

MILES, W. R. Static equilibrium. Methods med. Res, 1950, 3, 157-165.

PEZZOLI, J. A., \& MOORE, J. W. Conditional vestibular sway as a function of CS-UCS interval. Psychon. Sci, 1966, 5, 461-462.

REVUSKY, B. T. L., MOORE, J. W., \& DZENDOLET, E. Conditioning of the human vestibular sway response. Percept. mot. Skills, 1965, 20, 593-600.

TRAVIS, R. C. A new stabilometer for measuring dynamic equilibrium in the standing position. J. exp. Psychol., 1944, 34, 418-424.

TRAVIS, R. C. An experimental analysis of dynamic and static equilibrium. J. exp. Psychol, 1945, 35, 216-234.

von BEKÉSY, G. Über akustische Reizung des Vestibularapparatus. Pflug. Arch., 1935, 236, 59-76.

\section{NOTES}

1. This investigation was supported in whole by Public Health Research Grant NB 03675-05 from the National Institute of Neurological Diseases and Blindness. We are grateful to G. Griffin for his running of a preliminary study for this experiment.

2. Address: Department of Psychology, Middlesex House, University of Massachusetts, Amherst, Mass. 01003.

(Accepted for publication May 20, 1968.) 